University of Nebraska - Lincoln

DigitalCommons@University of Nebraska - Lincoln

Architectural Engineering -- Faculty Publications

Architectural Engineering and Construction,

Durham School of

2011

\title{
An Adaptive Photovoltaic-Inverter Topology
}

Mahmoud Alahmad

University of Nebraska - Lincoln, malahmad2@unl.edu

Mohamed Amer Chaaban

University of Nebraska-Lincoln, mchaaban@unomaha.edu

Siu Kit Lau

University of Nebraska-Lincoln, slau3@unl.edu

Follow this and additional works at: https://digitalcommons.unl.edu/archengfacpub

Part of the Architectural Engineering Commons

Alahmad, Mahmoud; Chaaban, Mohamed Amer; and Lau, Siu Kit, "An Adaptive Photovoltaic-Inverter Topology" (2011). Architectural Engineering -- Faculty Publications. 47.

https://digitalcommons.unl.edu/archengfacpub/47

This Article is brought to you for free and open access by the Architectural Engineering and Construction, Durham School of at DigitalCommons@University of Nebraska - Lincoln. It has been accepted for inclusion in Architectural Engineering -- Faculty Publications by an authorized administrator of DigitalCommons@University of Nebraska Lincoln. 


\title{
An Adaptive Photovoltaic-Inverter Topology
}

\author{
Mahmoud. Alahmad, Mohamed Amer Chaaban, Siu Kit Lau, \\ malahmad2@unl.edu, mchaaban@unomaha.edu, slau3@unl.edu \\ University of Nebraska-Lincoln
}

\begin{abstract}
Adaptive photovoltaic (PV) system is proposed. An improvement in the power generation of the system during different operating conditions is achieved. The proposed configuration provides flexible connection between the PV modules and the inverters to meet current conditions of $P V$ array. Preliminary simulation results are provided for an adaptive PV array. Efficiency comparison between traditional PV system configurations is discussed. Potential improvement using the proposed adaptive configuration is sited.
\end{abstract}

Index Terms - Reconfigurable PV, PV model, Switching Matrix, Inverter, Low radiation.

\section{INTRODUCTION}

$\mathrm{T}$ HE use of power generated from solar systems has recently become more common. because of the environmental threats arising from the production of electricity from fossil fuels and nuclear power Photovoltaic (PV) power supplied to the utility grid is gaining more and more visibility, while the global energy demand is inflating. Not many $\mathrm{PV}$-systems have been implemented into the grid due to the relatively high cost and modest efficiency. Although the efficiency of PV panels is still poor, the PV energy is a great opportunity for several applications including residential and commercial buildings, electrical vehicles, water pumping systems, and rural applications. There are two types of PV system: the off-grid, also known as stand-alone system, which consists of PV array, storage system, and power conditioning unit; and the grid connected system, which consists of PV array and power conditioning units.

Increasing the efficiency of the PV system is one of the most important parameters to promote greater adoption. Different area of focused research have moved to achieve this goal at the cell, module, array and system level; where a module consists of connected PV cells in one frame and array is a complete PV unit consisting of connected modules with structural support. The performance of the system not only dependant on the operating conditions such as shadowing, high temperature, or degradation of electrical characteristics of several damaged panels, but they also are strongly dependent on the PV system configuration. In other words, the interface, connection, and the configuration between system components are vital to achieving the accepted performance of the system, thus promoting $\mathrm{PV}$ installation in wide ranges.

Although, lots of research is focused on how to improve the efficiency of $\mathrm{PV}$ cells by improving the semiconductor behavior during manufacturing stage, active research focuses on improving the system performance by seeking the best operating conditions for the PV system, optimum configuration topologies and implementing power electronics devices to improve the overall efficiency. In [1] a reconfiguration at the cell level is discusses to address the shading effect and increase output power by adding additional external reconfigurable cells. In [2], [3], the concept of reconfiguration to match dissimilar cells to improve the efficiency is also addressed. However, this proposed reconfiguration incorporates a large number of switches and sensors at cell level, hence, leading to a complex system. In [4], an Electrical Array Reconfiguration [EAR] is proposed at the module level using a switching matrix. The proposed system is used to maximize the available DC power by matching similar modules with similar operating conditions. In [5], reconfiguration is proposed for an electric vehicle to increase the power output and operate the load at desired conditions to improve the load efficiency. For example, during acceleration, the engine requiring additional torque is supplied by reconfiguring the $\mathrm{PV}$ in parallel to increase the current output. In [6] the optimum switching points for array reconfiguration controller is discussed according to the irradiation conditions.

A new system configuration approach using adaptive PV system based on a switching matrix topology and different inverter configurations is proposed in this paper. This architecture is integrated to increase the PV system efficiency and serves as a potential reference for new applications in this field. The sections in the paper cover, in section II, existing PV system configurations, in section III, the proposed topology, in section IV Analysis of PV systems, and the conclusion in section $\mathrm{V}$.

\section{II.EXISTING PV SYSTEM CONFIGURATIONS}

The available system configurations in PV field vary according to the size and the function of these systems. In this section, the common configurations for grid connected PV system will be briefly discussed.

The central inverter system is shown in Fig.1 (a), where all strings are connected to a common inverter that converts the power from Dc to Ac to supply the grid. This system has the advantage of low cost; but it cannot correctly track the maximum power point (MPP) for the whole array [7], [8]. This is because each string has its own MPP according to the operating conditions and shading effect. This system also has 


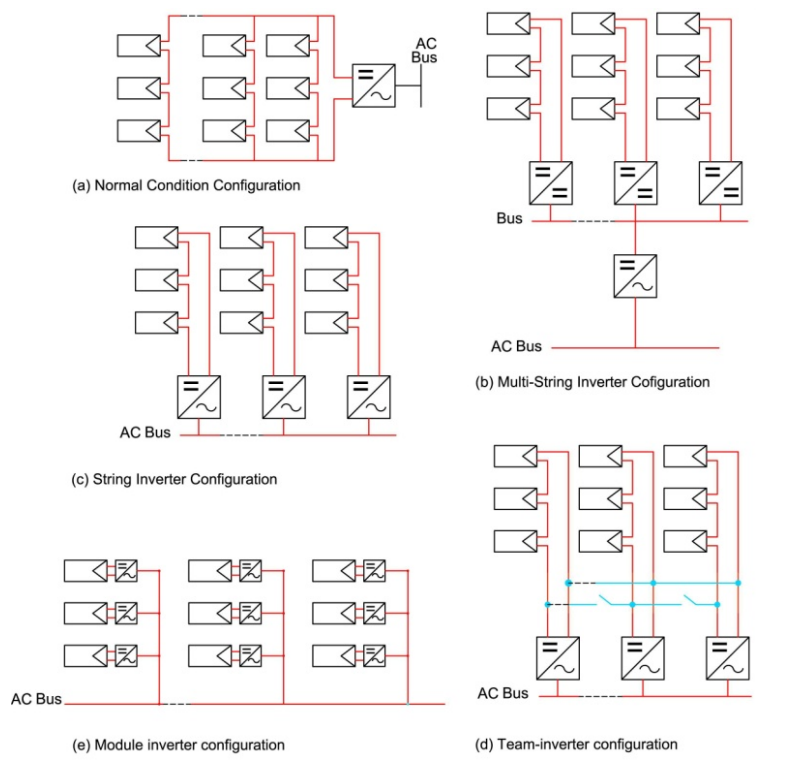

Fig. 1: PV System Configurations

one connection point which lead to a system failure when the inverter is faulty.

Multi-string inverter system is developed in order to improve the central inverter system performance in shading condition, the string inverter is shown in Fig.1 (b). This system has the ability to follow the MPP of each string independently [7], [8].

String inverter topology is shown in Fig.1 (C). In this configuration, each string has its own inverter and all inverters work in parallel to supply the load. This system has another advantage of increasing the system efficiency, with increased cost [7], [8] , [13]. Another system topology, the team inverter topology, uses controllable switches to connect between the parallel string inverters [7]. According to the solar insolation, the system connects the proper number of strings in parallel to a specific number of parallel inverters that will lead to achieving optimal efficiency of the connected inverters. The idea came from the fact that in low irradiance conditions, the generated energy from each string in the PV system does not match the optimal working efficiency of the inverters. Therefore, by adding more than one string in parallel and connecting them to a suitable number of inverters, the energy will match the optimal working point of the chosen inverter(s). This configuration is shown in Fig.1 (d).

The last common configuration is the module-Inverter (micro-inverter) system shown in Fig.1 (e), each single module is connected to a specific inverter that can individually operate near the module's MPP. Thus, the efficiency of the whole system is increased [4], [7], [13], but this method requires a large number of inverters (equal to the number of solar modules).

\section{THE PROPOSED ADAPTIVE PV-INVERTER SYSTEM}

A simplified block diagram of the proposed adaptive system layout is shown in Fig.2. The proposed approach offers a

flexible connection to rearrange the solar modules according to the operating condition. Using a switching matrix topology

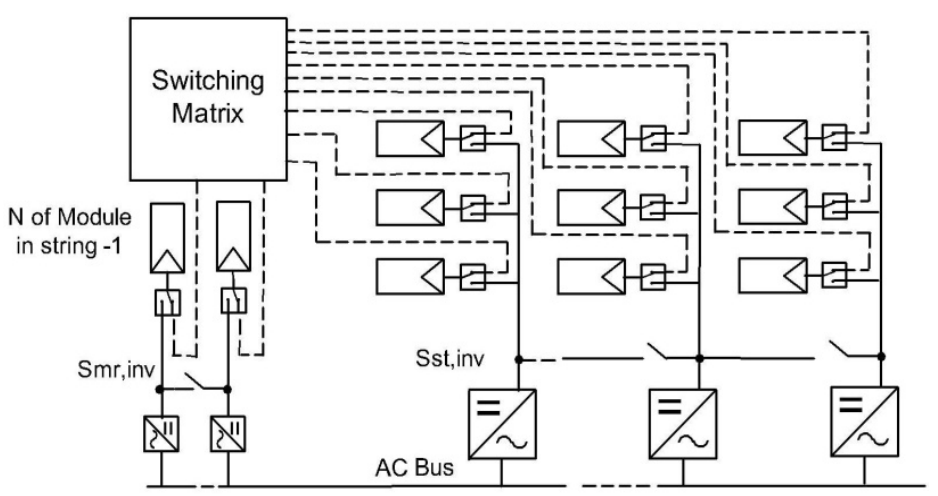

Fig.2: The Proposed Topology

and suitable Inverters configuration, the system will extract the maximum potential power efficiently from the PV array by adopting to the best operating conditions. For example, in low radiation condition, the matrix will reconfigure the system and utilize the micro/string inverters to achieve the best operating conditions based on real time conditions. The system consists of five major components: the string-PV modules, the microPV modules, the switching matrix, the micro inverters, and the string inverters.

\section{A. The Switching Matrix}

The matrix topology that reconfigures the connections between PV modules is similar to that proposed in [14] as shown in Fig.3. All PV modules, string-modules, micromodules, switches, and buses are the components of the switching matrix.

\section{a) The Matrix Architecture}

The matrix consists of switches and buses. The matrix can arrange the modules in two categories. The first is called PV string, which has multiple series connection of PV modules. The other is micro PV string, which consists of only one PV module that is called micro-module.

The switches are categorized according to their function. $\left(\mathrm{S}_{\mathrm{sr}}\right)$ are switches used to achieve the series connection between PV modules. The series connection may happen between nonadjacent modules; for example, between the first and the third module. This connection is achieved using switch $\mathrm{S}_{\mathrm{by} 2}$ in addition to $\mathrm{S}_{\mathrm{sr} 1}$. $\left(\mathrm{S}_{\mathrm{by}}\right)$ are switches that allow modules to be removed from the configuration. In the last example, the connection between the first and the third module is achieved using $\left(\mathrm{S}_{\mathrm{by}}\right)$ bypassing the second module. $\left(\mathrm{S}_{\mathrm{pu}}\right)$ are switches that connect the positive terminal of module to the positive buses. Activating any of the switches will establish the end of the string. $\left(\mathrm{S}_{\mathrm{pd}}\right)$ are switches that connect the negative terminal of module to the negative buses. Closing any of the switches will determine the beginning of the string. $\left(S_{\mathrm{st}, b u s,} \mathrm{~S}_{\mathrm{mr}, \mathrm{bus}}\right)$ are switches that allow the parallel connection between strings. For example, to connect first string to the second string switch $\mathrm{S}_{\mathrm{st}, \mathrm{bus} 1}$ is activated. 


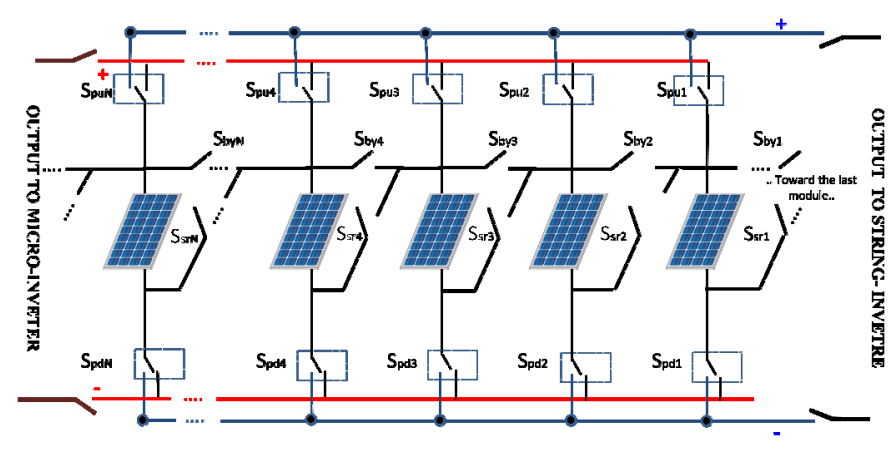

Fig. 2: The Switching Matrix

Two different types of buses are used to connect PV modules to the inverters. The first type is the string-buses that connect the PV strings to the string-inverters. The second type is the micro-buses that connect the micro-PV modules to the micro- inverters. For example, in normal condition each string will be connected to string-inverter through a string-bus and each of the micro-PV modules will be connected to the microinverter through micro-bus.

For a 8-module PV array, 42 switches are required. Four buses are used in this system; two string-buses are used to connect two PV strings to the string-inverters; the other two buses are micro-buses used to connect two micro-PV modules to micro-inverters. These buses are considered the point of common connection of the PV modules to supply the inverter.

The number of switches in the matrix depends on the number of modules in the PV array. Each module requires four switches in order to achieve the adaptive system. Each bus requires two switches to connect the PVs to the inverter and two switches between the PV strings/micro-PVmodules; hence:

$$
\begin{aligned}
N s w= & 4 \cdot(\text { Nmod })+2 \cdot(s t, i n v)+2(m r, i n v)+ \\
& (s t, i n v-1)+(m r, i n v-1)
\end{aligned}
$$

Where:

Nsw: is the total number of switches,

Nmod: is the number of modules in PV array,

(st,inv) and (mr,inv) are for the number of string-inverter and micro-inverter switches, respectively.

\section{b) The Matrix Operation}

In order to explain the matrix operation, illustration 1, 2, 3 and 4 are provided. The illustrations are built according to the PV array shown in Fig. 2 with three strings and three modules in each string.

\section{(1) Illustration 1 (Normal operation)}

The desired configuration is shown in Fig.4 (a), All modules are active. The matrix will activate the series switches $\mathrm{S}_{\mathrm{sr} 2}$, and $\mathrm{S}_{\mathrm{sr} 3}$ to complete the required number of modules in series in the first string, and this process will be applied to the second string by activating $\mathrm{S}_{\mathrm{sr} 5}$ and $\mathrm{S}_{\mathrm{sr} 6}$. In order to connect the PV strings to the inverters, the matrix inactivates $\mathrm{S}_{\mathrm{sr} 1}, \mathrm{~S}_{\mathrm{sr} 4}$, and $\mathrm{S}_{\mathrm{sr} 7}$. The parallel switches $\mathrm{S}_{\mathrm{pd} 1}, \mathrm{~S}_{\mathrm{pu} 3}$ will also be activated to connect the first PV string to the first string-bus. Switches $\mathrm{S}_{\mathrm{pd} 4}, \mathrm{~S}_{\mathrm{pu} 6}$ will be activated so that the second PV string connects to the second string-bus. In this case, the bypass switches $\left(\mathrm{S}_{\mathrm{by}}\right)$ will be inactivated. Each micro-PV module will be separately connected to each microinverter via a micro-bus.

\section{(2) Illustration 2 (Two shaded modules)}

Two shaded modules from different strings are examined. The desired configuration is shown in Fig.4 (b). The series switches $\mathrm{S}_{\mathrm{sr} 1}$ and $\mathrm{S}_{\mathrm{sr} 6}$ of the shaded modules will be inactivated. At the same time, the bypass switches $S_{\text {byl }}$ and $\mathrm{S}_{\text {by5 }}$ will be activated to connect the modules which are nonadjacent in series. For example, modules number 5 and 7. If the matrix does not have the number of modules in series in the string completed, the procedure will continue in order to achieve the required number of modules in the PV string. in this case, The first string will start with module number 2.

The parallel switches will be activated when the number of modules in series in the string is matching the required number of modules in the string. Then, switches $\mathrm{S}_{\mathrm{pd} 2}$ and $\mathrm{S}_{\mathrm{pu} 4}$ will be activated in order to connect the first string to the string-bus then to the first string-inverter and this process will be applied to the second string by activating $\mathrm{S}_{\mathrm{pd} 5}$ and $\mathrm{S}_{\mathrm{pu} 7}$. In this case, the array has one remaining module that does not meet the requirement to build a string and it can also generate energy. The matrix will consider this module as micro-module and will connect it to the micro-bus then to the micro-inverter.

\section{(3) Illustration 3 (Three shaded modules)}

Three shaded modules, two from different strings and one shaded micro-PV module, are examined. The desired configuration is shown in Fig.4(c). The series switches $\mathrm{S}_{\mathrm{sr}}$, $\mathrm{S}_{\mathrm{sr} 5}$, and $\mathrm{S}_{\mathrm{sr} 8}$ of the shaded modules will be opened. The bypass switches of these modules will be activated to connect the modules, which are nonadjacent, in series. Switches $\mathrm{S}_{\mathrm{pdl}}$, $\mathrm{S}_{\mathrm{pu} 4}$ of the first string will be activated. In this case, the array does not enough modules to build another string. That means the matrix will consider them as micro-PV modules and will connect them separately to micro-buses then to the microinverters.

\section{(4) Illustration 4 (low radiation)}

The case of low radiation across PV modules is examined. The desired configuration is shown in Fig.4(d). The matrix will arrange the modules exactly as the configuration during normal operating condition (Illustration 1). The only difference will be the connection to the inverters. Switches $\mathrm{S}_{\mathrm{st}, \text { inv1 }}$ and $\mathrm{S}_{\mathrm{st}, \text { inv2 }}$ will be activated to connect the string-buses in parallel to only one string inverter. This process will also be applied to the micro-buses by activating $\mathrm{S}_{\mathrm{mr} \text {,inv1 }}$ and $\mathrm{S}_{\mathrm{mrr}, \text { inv2 } 2}$ to connect the micro strings in parallel. For more detailed discussion about purpose of this illustration refer to (C.3) in this section.

\section{B. Control System}

The reconfiguration strategy is based on the fact that the switching matrix has to rearrange the active PV modules in series into multiple strings to meet the required voltage level of each PV string. The control algorithm of the switching matrix is illustrated by the flow chart in Fig 5. The controller does the following functions: first of all, identify module 


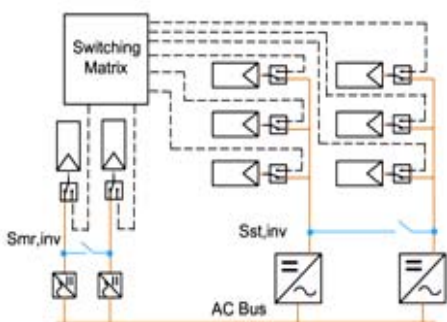

(a) Normal Operation conflguration

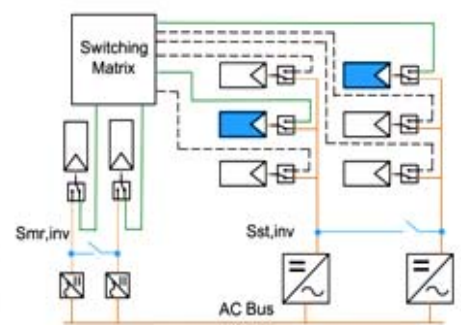

(b) Two-Shaded Modules configuration
Fig. 4: Different Configurations for Switching Matrix

conditions based on system parameters. If full-shading/fault exists, then a) disconnect the shaded modules b) reconfigure the active modules into strings and micro-strings. If shading does not exist, then the matrix will configure the modules in the normal configuration. The controller will arrange the modules in strings and micro strings. To accomplish that, each module is examined to determine whether it is shaded or not and also if it is located in the beginning of the string, in the end of the string, or in the middle of the string. In order to know the location of the modules in the sting, pointers are used to locate them accurately. For example, In case of nonshaded module, the controller will put the active module in the string. When the controller examines the next module, the controller will also examine the string whether the string is full or not. If the string is not full, the controller will connect the module in series to the other modules that are in the same string; Once the string becomes full (the pointers gives a signal that this module is at the end of string), the controller will arrange the other modules in micro-strings. In case of low radiation, the controller will exactly arrange the modules as the case of normal condition, which consists of strings and micro strings. The controller will then connect the strings in parallel to the suitable number of string-inverters and also will connect the micro-strings in parallel to micro-inverters.

\section{Advantages of Inverter Based Adaptive System}

In order to introduce the advantages of the proposed topology, some problems in traditional PV system will be discussed in this section.

\section{Shading Effect in PV Array}

One of the most undesirable cases in PV system that adversely changes the performance is the shading effect.

Significant reduction of the generated power from the solar PV array occurs when the shading happens across some of PV modules in the PV array, leading to extra losses [1]. The hot spot in the shaded part of the solar PV array is also one of the undesired effects that can damage the solar cells. Several methods have been proposed to reduce the effect of shadows on a solar PV array's power output.

The traditional method uses bypass diodes and blocking diodes. Almost all systems use bypass diodes, which are connected across shadowed modules, to pass the full amount of current while preventing a massive damage to the solar module. This method usually requires a huge number of bypass diodes that are integrated in the solar modules. The production of solar modules with bypass diodes is more

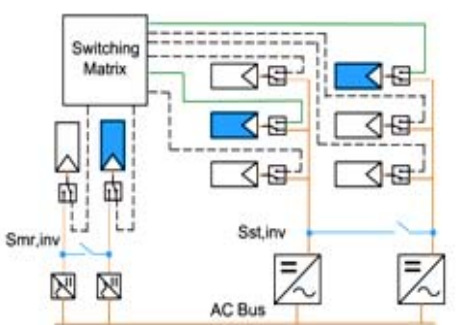

(c) Three-Shaded Modules configuration

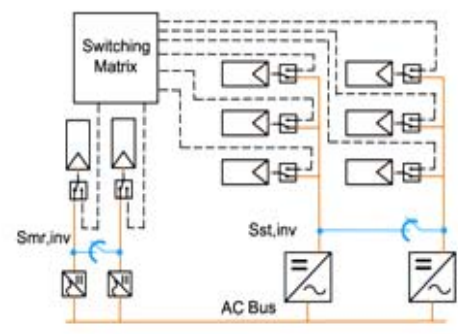

(d) Low Radiation configuration costly. Furthermore, the power losses of solar PV arrays are not completely prevented because there are additional power losses when the current passes though the bypass diodes.

Another disadvantage of bypass diodes is the multiple peaks in power curve of PV array output, as will be shown by Fig. 6. Having these multiple peaks lead to other losses in the system. When the MPP tracker tries to follow the MPP, it will be very difficult for MPPT to find the optimal maximum of these multiple peaks. This leads to develop an advanced MPPT to solve this problem. However, extra cost and the difficult control algorithm of the MPPT arise. The MPPT has to follow the global peak of power curve and avoid the local peaks that fluster the MPPT [9], [11]. Fig.6 shows the local and global peaks in power curves during shading condition.

\section{Mismatching Effects}

The other important phenomenon in PV filed is the mismatching effect of unequal voltage between strings that occurs because of dissimilarity between the voltages of the modules in different strings [8]. In order to solve this problem, blocking (string) diodes are used in each string to prevent the back feed current between strings. This method is beneficial but has also additional losses that will be added to PV system losses.

In the adaptive system concept, which offers flexible connections between modules, the shaded module can be eliminated by disconnecting it from the array. The process can be achieved by the switching matrix and the control algorithm that selects the optimum configuration after removing the shaded modules. Using this system, the electrical losses caused by bypass diodes and blocking diodes are minimized.

Another advantage of adaptive system is to avoid the multiple peaks phenomenon in power curve that occurs because of bypass diodes in traditional PV system (Fixed system). In this case a simple MPPT can be used instead of the complex one. Fig. 6 and Fig. 7 show the comparison between the output curves of adaptive and fixed systems during shading conditions. Improvement in the adaptive system curve is seen. There are no longer local peaks and the system works as normal operating condition.

\section{The Inverter Performance Characteristics}

The efficiency of the grid connected inverter depends significantly on the ratio of the DC generated power to the nominal power of the inverter as shown in Fig. 6. The performance of inverters is determined by the EURO efficiency $\eta_{\mathrm{EU}}$ or California efficiency $\eta_{\mathrm{Cal}}$ [17], [18]. For example in the morning, when low radiation occurs across PV modules, the total generated power of each string decreases to 


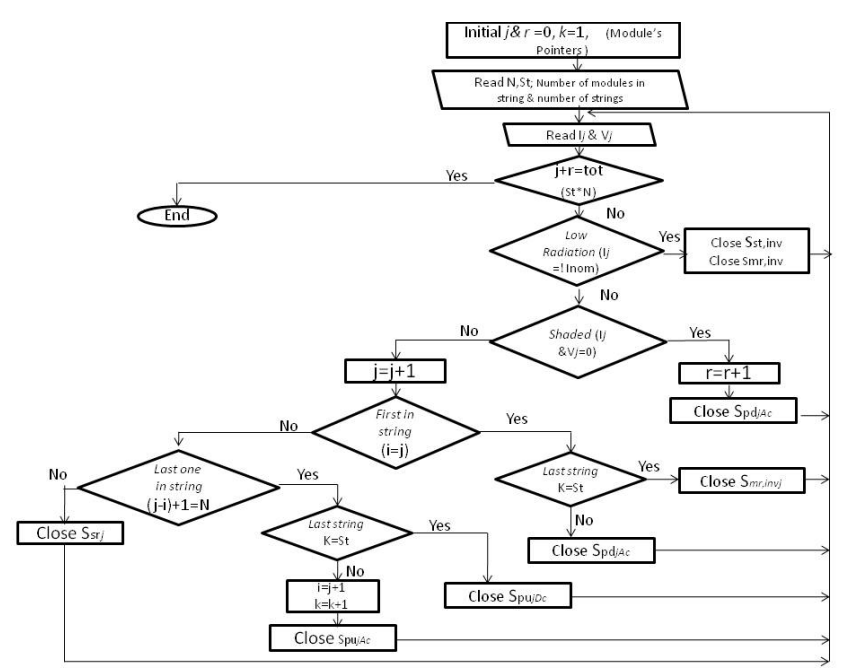

Fig. 5: The Control flow chart

a value that force the string inverter to operate at a low efficiency point that leads to extra losses in the system. In the adaptive system, the matrix can connect the strings in parallel to increase the total power provided to the string inverter. In this case the system will work as team-concept configuration. Another important value for the inverter is the optimum input DC voltage level that should also be taken into account in order to achieve the highest weighted efficiency. For example, for the same inverter, the efficiency will vary by changing the input voltage according to the inverter characteristics [15], [16]. There is no general rule about the dependency of inverter conversion efficiency on DC input voltage. There are inverters that have their maximum efficiency at low voltages but there are also inverters that have their top efficiencies at high voltages and also inverters that have their maximum efficiencies at a medium DC.

The concept of adaptive PV system allows us to rearrange the modules in different configuration and connect them to different inverters to match its maximum efficiency.

\section{ANALYSIS OF PV SYSTEMS}

\section{A. The Mathematical Calculation}

The losses in the inverter due to variation in the input power during the day are known as Weighted Efficiency, as systems are installed in a wide range of solar resource regimes [17]. For instance, if the inverter is oversized and the solar resource is marginal, the Weighted Efficiency would be a better predictor of system performance. Weighted Efficiency is calculated using the data taken at various levels of power according to the equation

$$
\begin{aligned}
& \eta_{w t d}=F_{1} \cdot \eta_{5}+F_{2} \cdot \eta_{10}+F_{3} \cdot \eta_{20}+F_{4} \cdot \eta_{30}+F_{5} \cdot \eta_{50} \\
& +F_{6} \cdot \eta_{75}+F_{7} \cdot \eta_{100}
\end{aligned}
$$

Where:

$\eta_{5}, \eta_{10}, \eta_{20}, \eta_{30}, \eta_{50}, \eta_{75}$, and $\eta_{100}$. - measured efficiency values at $5 \%, 10 \%, 20 \%, 30 \%, 50 \%, 75 \%$, and $100 \%$ of rated power. $F_{1}, F_{2}, F_{3}, F_{4}, F_{5}, F_{6}$, and $F_{7}$ - the weighting factors defined in Table 1.
TABLE 1

\begin{tabular}{|c|c|c|c|c|}
\hline \multicolumn{5}{|c|}{ Factor Inverter Power Weighting Factor } \\
\hline Factor & Power level & High-Insolation $^{1}$ & Low-Insolation $^{2}$ & Effic. Values \\
\hline F1 & $5 \%$ & 0 & 0.03 & 0.85 \\
\hline $\mathrm{F} 2$ & $10 \%$ & 0.04 & 0.06 & 0.93 \\
\hline F3 & $20 \%$ & 0.05 & 0.13 & 0.957 \\
\hline F4 & $30 \%$ & 0.12 & 0.1 & 0.96 \\
\hline F5 & $50 \%$ & 0.21 & 0.48 & 0.962 \\
\hline F6 & $75 \%$ & 0.53 & 0 & 0.96 \\
\hline F7 & $100 \%$ & 0.05 & 0.2 & 0.957 \\
\hline
\end{tabular}

The Inverter Weighting factors [17, Table 5-5]

1 - Based on irradiance and temperature data of Southwest US.

2 - Also known as European Efficiency.

TABLE 2

Comparison between inverter efficiencies for PV configurations

\begin{tabular}{|c|c|c|c|}
\hline \multirow{2}{*}{$\begin{array}{c}\text { Geographical } \\
\text { Locations }\end{array}$} & \multicolumn{3}{|c|}{ Losses in the Efficiency of the Inverters } \\
\cline { 2 - 4 } & Central-Inverter & String-Inverter & Micro-Inverter \\
\hline Omaha & 2.8 & 2.9 & 3 \\
\hline LA & 2.3 & 2.4 & 2.4 \\
\hline Phoenix & 2.5 & 2.9 & 2.9 \\
\hline Miami & 2.3 & 2.5 & 2.5 \\
\hline Seattle & 3.5 & 3.7 & 3.8 \\
\hline Boston & 2.9 & 3 & 3 \\
\hline
\end{tabular}

In Adaptive system, equation (2) will be modified in which the losses in the inverter due to different efficiency values can be eliminated. The new equation may have single factor to affect the overall efficiency. Future work will discuss it is details.

\section{B. The Analysis Tools}

Solar Advisory Model (SAM) is used to verify the result of the proposed system. The annual energy and efficiency of the system can be generated using SAM [10] for different geographical locations such as Omaha, NE, Los Angeles, CA, Phoenix, AZ, Miami, FL, Seattle, WA, and Boston, MA. Different geographical locations are chosen based on the U.S. Photovoltaic Solar Resource Fig.8 [10]. Each city represents different radiation zones in USA. In order to explain the advantage of the proposed system, a $4 \mathrm{~kW}$ grid connected PV system is analyzed. Configurations considered for analysis are the central PV system, strings system, and micro PV system. A three string system with 8 modules in series in each string chosen. The selected components are: Schott Solar 170Wp modules, Kaco new energy Gmbh : Bule planet 1502xi $240 \mathrm{~V}$ is taken as string inverter, Motech industries Icn. PVmate $4900 \mathrm{U} 208 \mathrm{~V}$ as central inverter and Enphase Energy M17524-240-S $240 \mathrm{~V}$ as micro inverter. 


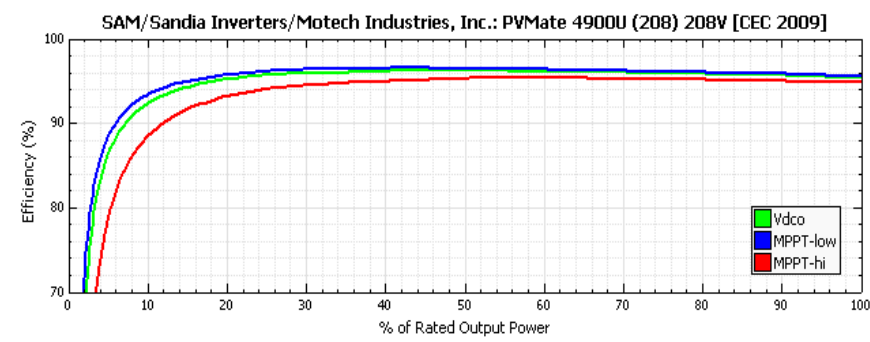

Fig. 6: The Central-Inverter's Efficiency-Power ratio Curve by SAM [10]

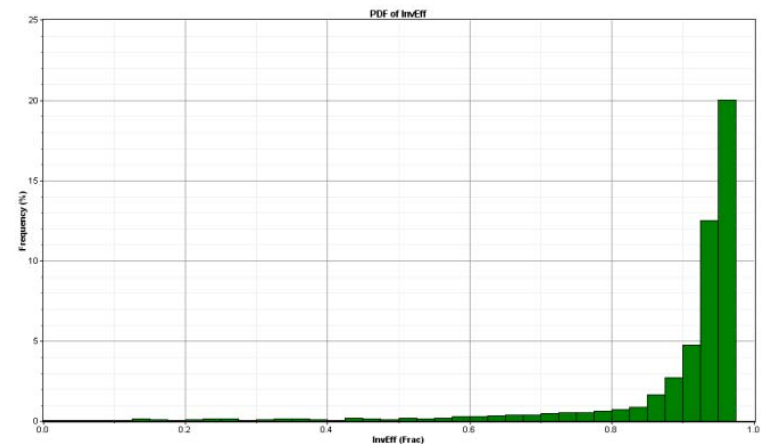

Fig. 7: PDF Curve of String-Inverter Efficiency, Seattle, WA by SAM [10]

The efficiency of each configuration is developed and compared. The probability distribution functions (PDF) of the inverter's efficiency and the deviations of the efficiency values from the nominal efficiency value are studied. The comparison results are shown in Table 2. PDF curve of the string inverter in Seattle,WA, is also shown in Fig. 7. The efficiency values are shown in the $\mathrm{X}$-axis while the probabilities are in the Y-axis. Both can be seen in Fig. 7. The highest column explains the nominal value of the inverter's efficiency. The other columns illustrate how frequent the efficiencies that do not meet the nominal value occur during one year. For example, the summation of the losses in Seattle is close to $4 \%$ yearly as shown in Table.2. In other words, the closer the values to the nominal efficiency, the smaller the losses in the inverter and the better the performance of the inverter.

\section{Efficiency comparison of PV System configurations}

In Table 2, a comparison study of the inverter efficiencies for the configurations sited in last section is developed. Reviewing the results, the same system installed in different geographical locations with different insolation and weather status can perform better in the stable insolation area. For example, in Phoenix, AZ, the system has yearly $3 \%$ losses in the inverter because of the efficiency responding characteristics, but in Seattle, WA, the system has approximately $4 \%$ losses because the radiation level varies. In other words, the annual low insolation portion in Seattle is larger than that in Phoenix. This conclusion gives the adaptive system more potential to be applied in such locations with unstable insolation areas as shown in Fig. 9. In order to illustrate the idea of losses in the inverter, an approximate study for inverter's efficiency PDF curves are taken for the high sample of efficiency value in Fig. 9. For example, Pheonix, AZ, has a good response because the radiation profile gives the inverter the ability to work at the optimal

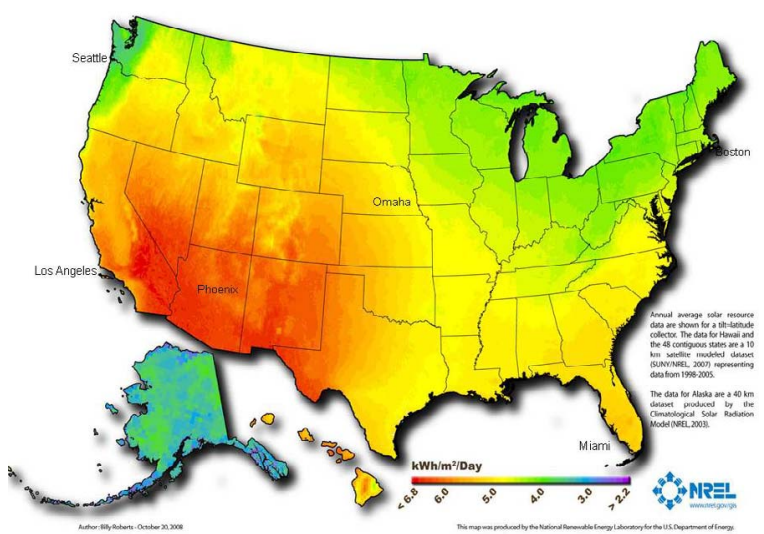

Fig. 8: U.S. Photovoltaic Solar Resource [10]

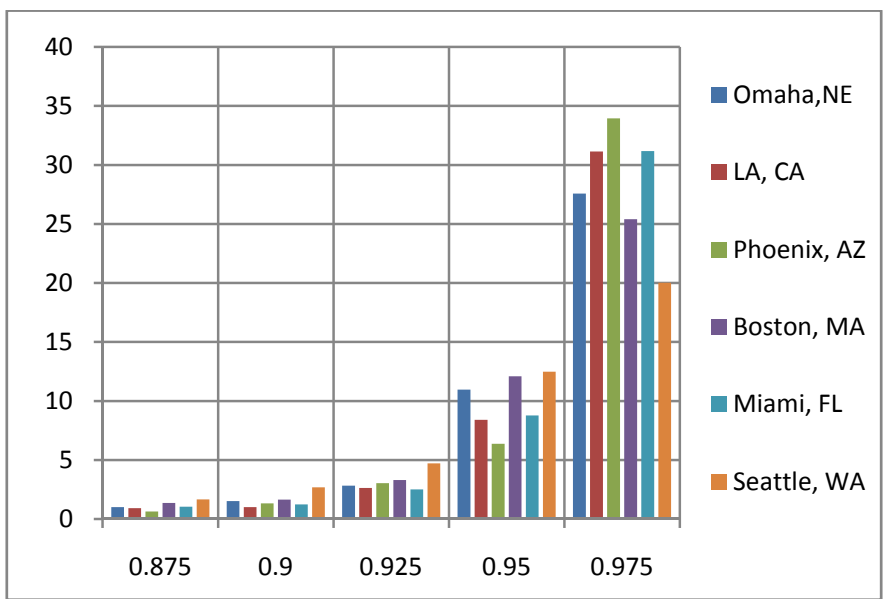

Fig. 9: PDF Efficiency Curves of string Inverters for different locations

efficiency but the high temperature issue should be taken into account to reach a perfect case. Another example is Seattle, WA, in this case, because of the solar raidiation profile, Different operating points of the inverter efficiency will occur and the total losses of will be more as shown in Table. 2.

In the adaptive system, the losses are minimized in the study because the system will operate at the inverter's optimal operating point by rearranging the PV modules in suitable configurations. However, SAM is not able to prove this conclusion, but the calculation does prove the improvement.

\section{V.CONCLUSION}

An adaptive PV-Inverter system is proposed and discusses in this paper for some applications in terms of shading to increase the efficiency of the PV system. The analysis results with SAM verify the behavior of traditional PV systems and compare them together. Calculation of the adaptive system is done to verify the performance improvement. New switching matrix architecture is proposed to achieve adaptive connection between PV modules, preliminary results for future research in adaptive PV-Inverter systems is discussed. Research to develop the exact control approach and to simulate the system is in progress. 


\section{ACKNOWLEDGEMENT}

This project is funded and sponsored by the United States Environmental Protection Agency (EPA).

\section{REFERENCES}

[1] D. Nguyen And B. Lehman "An Adaptive Solar Photovoltaic Array Using Model-Based Reconfiguration Algorithm". IEEE Tran. On Ind. Elec., Vol. 55, No. 7, July 2008

[2] C. Chang, "Solar Cell Array Having Lattice Or Matrix Structure And Method Of Arranging Solar Cells And Panels," U.S. Patent 6635 817, Oct. 21, 2003.

[3] R. A. Sherif And K. S. Boutros, "Solar Module Array With Reconfigurable Tile," U.S. Patent 6350 944, Feb. 26, 2002.

[4] G. Velasco, F. Guinjoan, R. Piqué, M. Román And A. Conesa. "Electrical Pv Array Reconfiguration Strategy For Energy Extraction Improvement In Grid-Connected Pv Systems". IEEE Transactions On Industrial Electronics, Vol. 56 No.11, Pp. 4319-4331, Nov. 2009, Issn: 0278-0046.

[5] Y. Auttawaitkul, B. Pungsiri, K. Chammongthai And M. Okuda. 'A Method Of Appropriate Electric Array Reconfiguration Management For Photovoltaic Powered Car'. The 1998 IEEE Asia-Pacific Conference On Circuits And Systems. (Apccas 98). Pg. 201 - 204. Chiang, November 1998.

[6] Z.M. Salameh And C. Liang. 'Optimum Switching Point For Array Reconfiguration Controllers'. IEEE 21st Photovoltaic Specialists Conference, 1990. (21st Pvsec). Vol. 2, Pg. 971 - 976. Kissimmee, May 1990.

[7] J. M. A. Myrzik, And M. Calais "String And Module Integrated Inverters For Single-Phase Grid Connected Photovoltaic Systems - A Review" 2003 IEEE Bologna Power Tech Conference, June 12th-26th, Bologna, Italy.

[8] S. B. Kjaer, J. K. Pedersen, F. Blaabjerg." A Review Of Single-Phase Grid-Connected Inverters For Photovoltaic Modules". IEEE Transactions On Industry Applications, Vol. 41, No. 5, September/October 2005.

[9] T. Esram, And P. L. Chapman' Comparison Of Photovoltaic Array Maximum Power Point Tracking Techniques' IEEE Transactions On Energy Conversion, Vol. 22, No. 2, June 2007.

[10] Solar Advisor Model (Sam), The National Renewable Energy Laboratory (Nrel). Free Download At Www.Nrel.Gov.

[11] H. Patel And V. Agarwal," Matlab-Based Modeling To Study The Effects Of Partial Shading On Pv Array Characteristics" IEEE Transactions On Energy Conversion, Vol. 23, No. 1, March 2008.

[12] Photovoltaic System, In Partnership With Njatc. 2008.

[13] Power Electronics Handbook. Editor-In-Chief Muhammad H. Rashid.

[14] M. A. Chaaban, And M. Alahmad "Adaptive Photovoltaic System", Iecon'2010 The 36th IEEE-IES Annual Conference, Nov. 7th-10th, Phoenix, Az, Usa.

[15] F. P. Baumgartner, H. Schmidt*, B. Burger, R. Bründlinger, H. Häberlin, M. Zehner "Status And Relevance Of The Dc Voltage Dependency Of The Inverter Efficiency". 22nd European Photovoltaic Solar Energy Conference And Exhibition, 3-7 September 2007, Fiera Milano, Session 4do.4.6.

[16] H. Haeberlin, L. Borgna, M. Kaempfer And U. Zwahlen "Total Efficiency $\mathrm{H}_{\text {tot }}$ - A New Quantity For Better Charachterisation Of GrogConnected Pv Inverters", $20^{\text {th }}$ European Photovoltaic Solar Energy Conference, Barcelona, Spain, June 2005.

[17] W. Bower, Sandia National Laboratories Solar Technologies, Albuquerque, Nm 87185-0703, C. Whitaker Endecon Engineering, W. Erdman, M. Behnke Bew Engineering, Inc. San Ramon, Ca. And M. Fitzgerald, Institute For Sustainable Technology, "Performance Test Protocol For Evaluating Inverters Used In Grid-Connected Photovoltaic Systems". Invertrtestproto_041014.Doc, Oct 2004. Usa.

[18] Nh. Reich1, W.G.J.H.M. Van Sark, E.A. Alsema, S.Y. Kan2, S. Silvester, A.S.H. Van Der Heide, R.W. Lof, R.E.I. Schropp, "Weak Light Performance And Spectral Response Of Different Solar Cell Typesn" 